\title{
Optimization of Hybrid Vehicle Drivetrain with Genetic Algorithm using Matlab and Advisor
}

\author{
Milan Biroš*, Karol Kyslan and František Ďurovský \\ Dept. of Electrical Engineering and Mechatronics, Faculty of Electrical Engineering and Informatics, Technical University of Košice, \\ Letná 9, 04200 Košice, Slovak Republic
}

Received 16 January 2017; Accepted 27 June 2017

\begin{abstract}
Advantages of hybrid vehicles over pure electric vehicles are obvious and well-known. The paper presents a simulation study of the optimization of hybrid propulsion drivetrain. A vehicle model was optimized in order to scale drivetrain components to achieve better fuel economy and lower greenhouse emissions. A set of ADVISOR data for vehicle was optimized by genetic algorithm in Matlab. Simulation results show significant fuel economy improvement.
\end{abstract}

Keywords: vehicle, optimization, genetic algorithms, Advisor, Matlab

\section{Introduction}

Increasing amount of people living in cities and sub-urban areas increase demand on personal transportation. Many people decide to use passenger car for commuting to their work. This causes several issues, such as a bad air quality in the cities and increasing fossil fuel consumption. The most preferable solution for these issues by car manufacturers is downsizing of combustion engine in vehicle. Due to limits of internal combustion engine (ICE), downsized motor with the same power characteristics requires advanced modifications, such as supercharging, what, unfortunately, increases the mechanical complexity of the drivetrain. Another approach for the city vehicle is using of alternative onboard power source, for example electric power. Electric vehicles have their limitations of which the most significant is driving range. Therefore, hybrid vehicles, which are the combination of ICE and pure electric vehicles, become more popular. Advantages of hybrids against ICE vehicles are following [1], [2]:

- lower fuel consumption and lower greenhouse gases emissions in urban driving,

- possibility of drivetrain overloading,

- possibility of energy recuperation at braking.

Power requirements of different vehicles to accomplish New European Driving Cycle (NEDC) are shown in Table 1. If NEDC is the reference for urban driving, it may be seen that modern passenger vehicles dispose much more power than they need. Additional power is needed in some situations, such as heavy acceleration during fast overtaking, trailer pulling, fast uphill driving, which occurs occasionally, but adds the weight and inefficiency permanently. Therefore,

\footnotetext{
"E-mail address: milan.biros@tuke.sk

ISSN: 1791-2377 @ 2017 Eastern Macedonia and Thrace Institute of Technology. All rights reserved. doi:10.25103/iestr.103.06
}

adding electric motor to cooperate with ICE come across as the most advantageous solution for two reasons. At first, it is possible to overload the electric motor, so vehicle may shortly dispose with more power it actually carries. Moreover, thanks to the ICE, its driving range is not limited by batteries and it must not be circuitously recharged, as in case of pure electric vehicle.

This paper presents the hybrid propulsion drivetrain downsizing method by using genetic algorithms (GA). The main objective is to scale drivetrain components to achieve better fuel economy and lower greenhouse gas emissions while maintaining vehicle ability to complete NEDC. Proposed algorithm was applied on Toyota Prius model in NREL's ADvanced VehIcle SimulatOR (ADVISOR) software [3].

ADVISOR is a set of model, data, and script text files for the use with Matlab and Simulink. It is designed for rapid analysis of the performance and fuel economy of conventional, electric, and hybrid vehicles. ADVISOR also provides a backbone for the detailed simulation and analysis of user defined drivetrain components. Therefore it is a starting point for verification of vehicle data and algorithms.

Table 1. Power requirements for NEDC

\begin{tabular}{c|c|c|c}
\hline Vehicle & $\begin{array}{c}\text { Mean } \\
\text { power }\end{array}$ & $\begin{array}{c}\text { Maximum } \\
\text { power }\end{array}$ & $\begin{array}{c}\text { Commercial } \\
\text { vehicle power }\end{array}$ \\
\hline Compact & $3 \mathrm{~kW}$ & $13 \mathrm{~kW}$ & $60 \mathrm{~kW}$ \\
Midsize & $4 \mathrm{~kW}$ & $14 \mathrm{~kW}$ & $80 \mathrm{~kW}$ \\
Sport & $4 \mathrm{~kW}$ & $16 \mathrm{~kW}$ & $200 \mathrm{~kW}$ \\
SUV & $7 \mathrm{~kW}$ & $28 \mathrm{~kW}$ & $150 \mathrm{~kW}$ \\
\hline
\end{tabular}

It allows taking the full advantage of modeling flexibility of Simulink and analytic power of MATLAB. ADVISOR does not allow the solution of the fuel efficiency [3]. This means that it may scales components to minimum size to complete the driving cycle, when it is set to corresponding constants. Minimum size components may not have minimal fuel consumption. Proposed algorithm scales vehicle components not to minimum size, but to size with the lowest fuel 
consumption. Furthermore, ADVISOR does not allow optimization of the series-parallel hybrid drivetrain. For that reasons, genetic algorithms have been chosen for the optimization.

GA are widely used for solving of multi-objective optimization or combinatorial problems which are difficult or impossible to solve by using conventional optimization methods. They are very popular for solving vehicle routing or scheduling problems [4]-[6] and vehicle shapes optimization problems [7]-[9] in the automotive engineering research.

In [10]-[12] authors concern to vehicle components optimization by using GA, but they were focused on the series hybrid vehicles only. Vehicle size optimization for series hybrid electric mini-bus for Beijing Olympic gymnasium in [10], where fuel consumption was improved of about $12 \%$. Papers [13]-[15] concern with the fuel cell hybrid bus and battery tram. In addition to fuel economy optimization, the components cost and the operating cost has been optimized. Parallel hybrid vehicle optimization by using GA was described in [16]-[17] with the consideration of the vehicle dynamics. Proposed algorithm optimize series-parallel hybrid vehicle with an emphasis placed on fuel economy.

\section{Model and Configuration of the Vehicle}

By default, ADVISOR software provides AUTOSIZE function. The purpose of this function is to help the user to generate a vehicle that will meet certain performance criteria. It accomplishes this by adjusting the component sizes and reevaluating the performance criteria until all of the specifications have been met. It uses bisection method and some build-in logic to determine the acceptable component sizes. It scales drivetrain components to minimum in order to meet acceleration and grade criteria.

Vehicle model in this paper is based on the first generation of Toyota Prius, which features the Toyota Hybrid System (THS). The configuration of the Prius vehicle drivetrain is shown in Fig. 1.

THS connects an engine (FC), generator (GC), and electric motor (MC) through planetary gear set (PGS). Component denominations correspond to ADVISOR.

Thanks to PGS, the amount of gear ratios between the engine and the vehicle speed is infinite by control of GC speed, so PGS is both a power summing device and a gear ratio device. Motor and generator allow bidirectional power flow so they are often referred to as Motor/Generator 1 (MG1) and Motor/Generator 2 (MG2). Only MC is connected directly to the wheels so it has rotate while the vehicle is moving. When the vehicle is driving only in electric mode (engine off), planet carrier in PGS is not moving and sun and ring are rotating in opposite directions. When $\mathrm{FC}$ is on, direction and speed of MC depends on the vehicle speed. GC speed and direction are given by gear ratios of $\mathrm{FC}$ and $\mathrm{MC}$ speed.

Table 2. Toyota Prius parameters

\begin{tabular}{c|c}
\hline Parameter & Value \\
\hline Total vehicle mass $[\mathrm{kg}]$ & 1332 \\
Aerodynamic drag coefficient [-] & 0.3 \\
Frontal area $\left[\mathrm{m}^{2}\right]$ & 1.746 \\
Rolling resistance coefficient [-] & 0.009
\end{tabular}
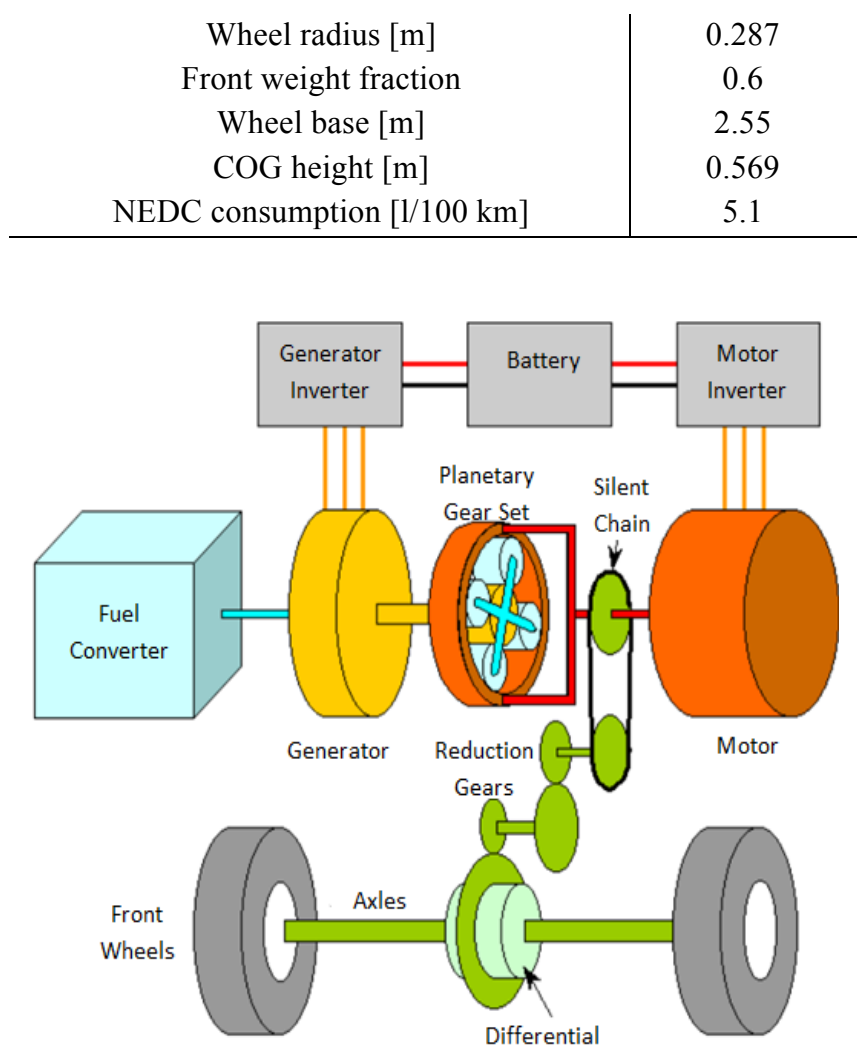

Fig. 1. Toyota Prius drivetrain configuration

Equivalent consumption minimization strategy (ECMS) is used to control Toyota Prius hybrid drivetrain, similarly as in [18]. ECMS is the control method, in which electric energy consumption is substituted by equivalent fossil fuel consumption. This strategy splits overall vehicle power requirement between FC and MC. Power ratio is considered as optimal when sum of fuel consumption of $\mathrm{FC}$ and equivalent fuel consumption of MC is minimal [19]-[20]. Vehicle parameters are shown in Table 2 . These parameters have been used in ADVISOR.

\section{Application of GA}

Genetic algorithms (GA) are based on Darwin's evolutionary principles, where attributes of each individual predestinate individual capability to survive in its environment or to die. The most beneficial attributes (genes) of individuals may be combined in the next generation and may create another individual, which should be more able to live. In each next generation, population individuals are more convenient for their environment. Random first generation with enough amount of descends in enough generations may finally generate the perfect individual.

There are two main differences between standard optimization methods and genetic algorithm. The first difference is that GA generates the set of solutions at each iteration, which approaches an optimal solution. The second difference is that a new generation computations involve random choices. Therefore, GA may be applied to solve optimization problems that are not well suited for standard optimization algorithms. For example, problems in which the objective function is discontinuous, nondifferentiable, stochastic, or highly nonlinear [21]. 


\section{Problem Formulation}

Drivetrain components of series-parallel hybrid vehicle have been scaled by using of genetic algorithm. Drivetrain components scale values presents genes of each individuals. Propriety of each individual is described by fitness function $\phi$ :

$$
\begin{aligned}
& \phi=f c+f c_{e q}+e, \\
& f c_{e q}=5,9.10^{-9} \frac{\sum_{i=1}^{n} P_{b a t t, i}}{n \eta_{b a t t} \eta_{f c} \eta_{g c}} \frac{t}{3600} \frac{100}{d},
\end{aligned}
$$

where:

$f_{c} \quad$ amount of the fuel consumed by engine $[1 / 100 \mathrm{~km}]$,

$f c_{e q} \quad$ equivalent fuel consumption of electromotor, $[1 / 100 \mathrm{~km}]$,

$e \quad$ error which denotes an ability to complete driving cycle [-],

$P_{\text {batt }} \quad$ requested power of battery [W],

$n$ number of samples [-],

$\eta_{\text {batt }} \quad$ battery efficiency [-],

$\eta_{f c} \quad$ ICE efficiency [-],

$\eta_{g c} \quad$ generator efficiency [-],

$t \quad$ driving cycle time [s],

$d \quad$ distance travelled during driving cycle [m].

Main aim of the optimization process is to minimalize fuel consumption. Therefore fitness is described as the sum of fuel consumed by engine and electric motor equivalent fuel consumption. Except minimum consumption, vehicle has to complete NEDC cycle. In case that vehicle is not able to complete it, error must be detected. Therefore, $e=1$ if difference between speed required by driving cycle and vehicle speed differs more than $3.2 \mathrm{~km} / \mathrm{h}$.

Equation (2) represents energy conversion from $\mathrm{kWh}$ to litres of gasoline. Is convenient to use relative values of its power during components optimization. They are presented as a scaling factor in ADVISOR.

Scaling factor $s_{n}$ is represented as reciprocal value of $n$ th component power $P_{n}$, as described in equation (3).

$$
S_{n}=\frac{1}{P_{n}}
$$

Original Prius drivetrain power values are listed in Table 4. Therefore, scaling factors for engine, motor and generator are as follows: 0,$023412 ; 0,032781$ and 0,066315 ; respectively.

Proposed GA flowchart is shown in Fig. 2. It optimizes three simulation parameters: engine torque, motor torque and generator torque. Initial set of parents consists of 20 individuals. Genes of individuals presents the scaling factor of each drivetrain component. Genes of initial parents are distributed uniformly within boundaries shown in Table 3 . Sizing using scaling factors determines components parameters approximately. For more accurate results, different approaches may be used [22] - [26].

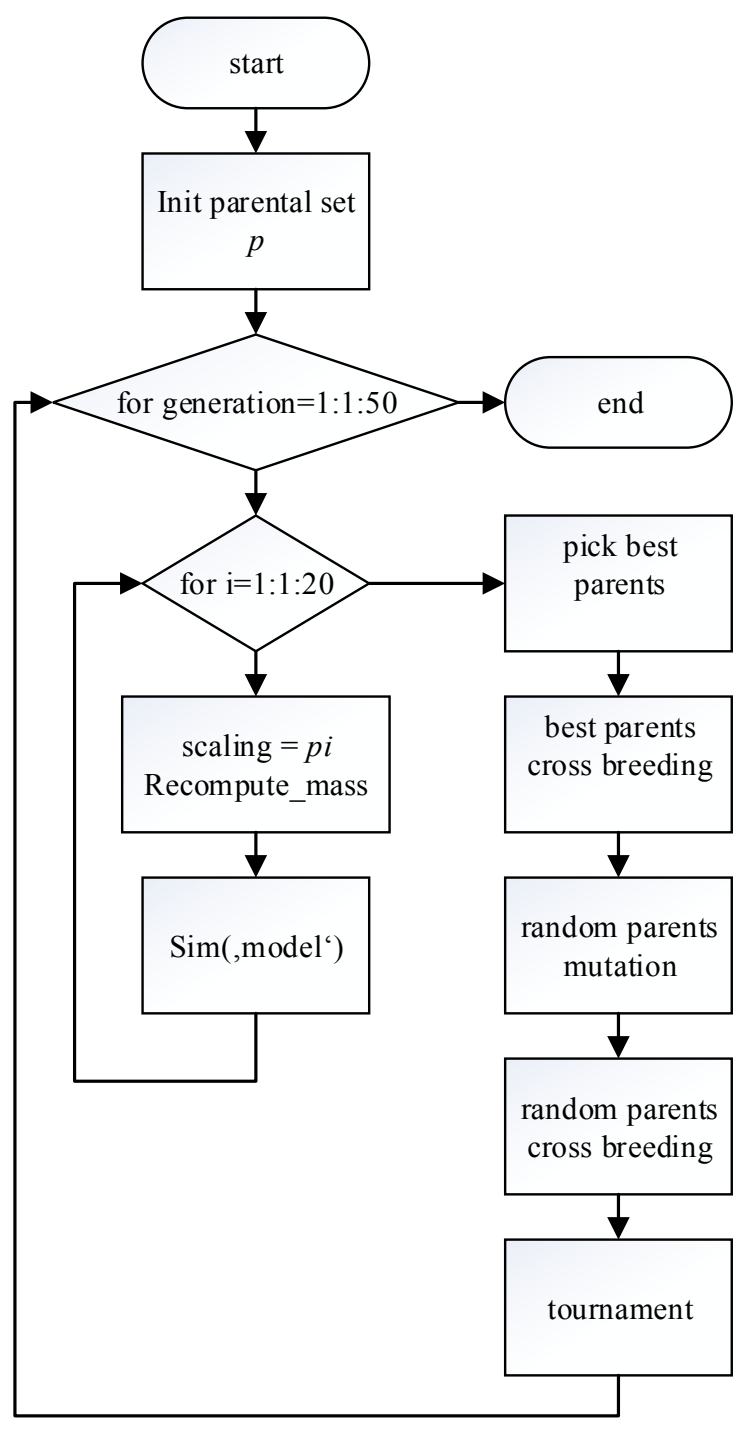

Fig. 2. A flowchart of proposed genetic algorithm

Creation of individual genes of parent set $p$ is described as follows:

$$
p_{m, n}=s_{n} L_{n}+0,05 m s_{n}\left(U_{n}-L_{n}\right),
$$

$$
\begin{array}{ll}
\text { where: } \\
m & \text { number of individual, } \\
n & \text { number of genome, } \\
U & \text { upper limit of individual genome, } \\
L & \text { lower limit of individual genome }
\end{array}
$$

Equation (4) regularly distributes values within chosen boundaries.

Table 3. Scaling boundaries

\begin{tabular}{c|c|c}
\hline & Upper bound & Lower bound \\
\hline Engine & $60 \mathrm{~kW}$ & $10 \mathrm{~kW}$ \\
Motor & $60 \mathrm{~kW}$ & $5 \mathrm{~kW}$ \\
Generator & $30 \mathrm{~kW}$ & $5 \mathrm{~kW}$ \\
\hline
\end{tabular}




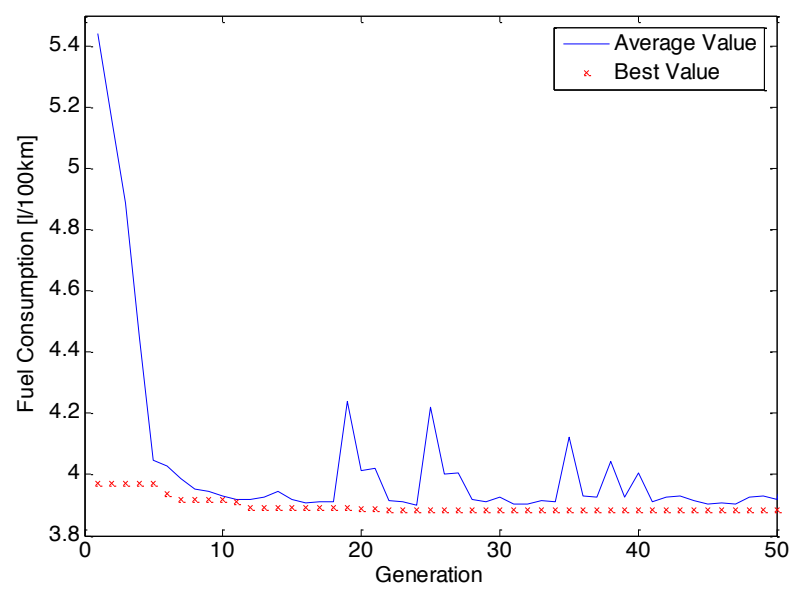

Fig. 3. Fuel consumption during optimization

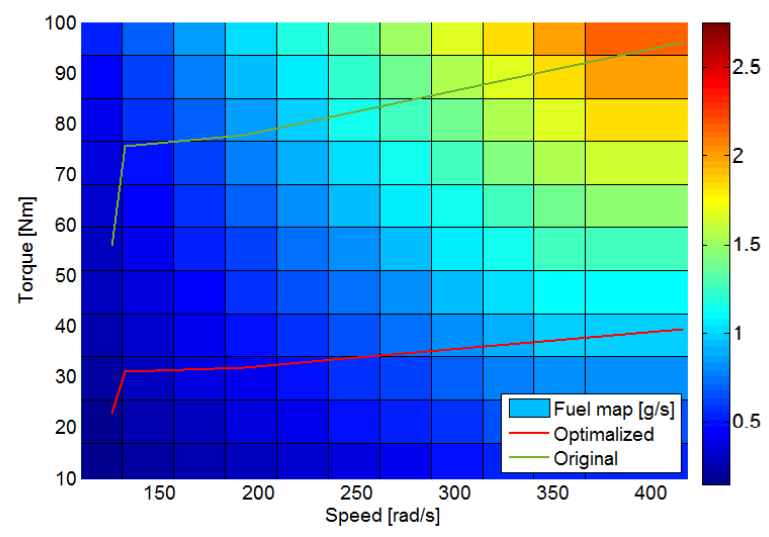

Fig. 4. Optimal engine torque curves

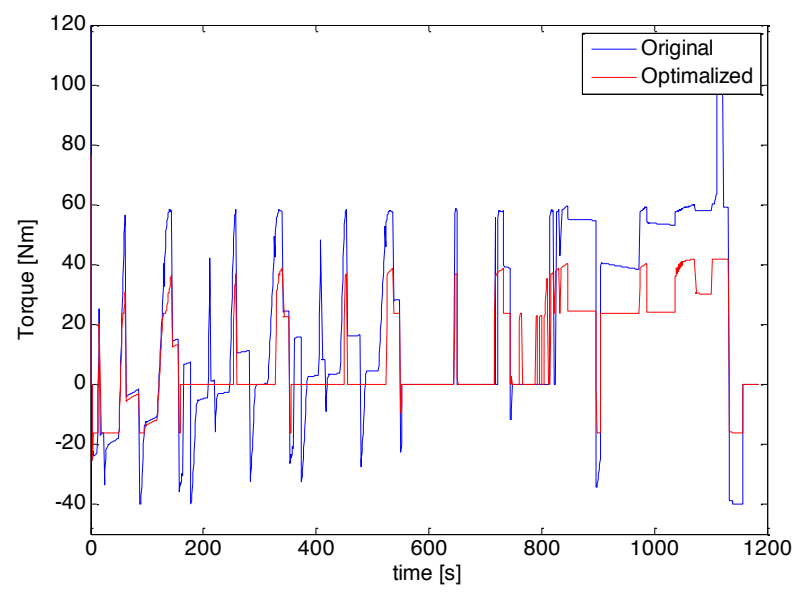

Fig. 5. Engine (FC) torque during NEDC

Each individual of parental set is evaluated by Matlab/Simulink simulation after initialization. Mass of all components has to be recomputed before evaluation. Two best parents are picked and survive to the next generation, so their presence in the next generation is guaranteed. Otherwise, it may happen that they wouldn't be picked into tournament and get lost. After that, they are crossbred and also survive to next generation. Next mutations and crossbreeds are applied on random genes of random remaining members of parental set. Set of descendants is supplemented by tournaments between random pairs of parents.

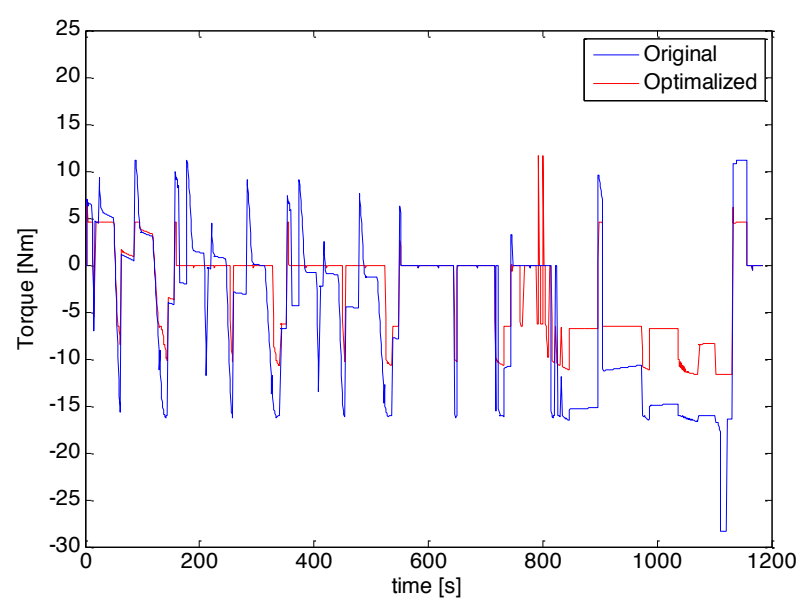

Fig. 6. Generator (GC) torque during NEDC

Number of generations was strictly defined to 50 , what was sufficient. Ending condition (5), where $\Phi_{g e n-1}$ and $\Phi_{g e n}$ is the best fitness in previous and actual generation and $\varepsilon$ is small positive integer, was not applied, because of the probability that algorithm will end before obtaining optimal value or it will end in infinite cycle.

$$
0<\left|\Phi_{g e n-1}-\Phi_{\text {gen }}\right| \leq \varepsilon
$$

\section{Results}

Fig. 3 shows fuel consumption over generations. It can be observed, that an average fuel consumption of the population decreased rapidly. It decreased of about 1.3 liters in 5 generations and the best value has appeared in the 21 st generation. Difference between the best value in $12^{\text {th }}$ and $21^{\text {st }}$ generation was only about 0.07 liter. Based on these results, we may consider proposed algorithm as very effective. Fuel consumption after optimization was lower due to the two facts. The first reason is that the overall vehicle mass was lower, what caused in lower rolling resistance and resistance during acceleration as well as lower energy recuperation during regenerative breaking. The second reason is that the optimal operating point of downsized engine lies in the area with lower fuel consumption, what can be observed in Fig 4. By comparison of Fig. 4 and Fig. 5 it may be seen, that optimized vehicle operates near maximum torque and speed whereas the original vehicle operates near maximum torque and lower speed (during peak torque demand). In general, FC reaches the highest efficiency operating near maximum speed and torque, it may be assumed that downsized FC is more efficient as original $\mathrm{FC}$.

Fig. 5 - Fig. 7 show torque demand distribution among engine, motor and generator, respectively. It can be observed that optimized vehicle engine provides less torque than original. Note, that optimization was realized by the component scaling, what caused reduced mass of the vehicle due to the reduced weight of optimized engine. The mass of the optimized vehicle is lower by $10 \%$ to a non-optimized vehicle (see Table 4). However, other vehicle parameters, such as drag coefficient, roll coefficient, etc.; remained unchanged. For these reasons, the engine torque drop has to be compensated by electric motor, what is shown in Fig. 7. 
Non-optimized drivetrain works the way that in nonoptimal operating point the engine it is loaded by the generator in order to reach optimal operating point. It follows that battery is charged by the generator not only during braking but even if the vehicle works non-optimally.

Optimized engine is downsized and so it disposes less power reserve. It is loaded by the generator less often, what causes less battery discharging, what can be observed in Fig. 8 .

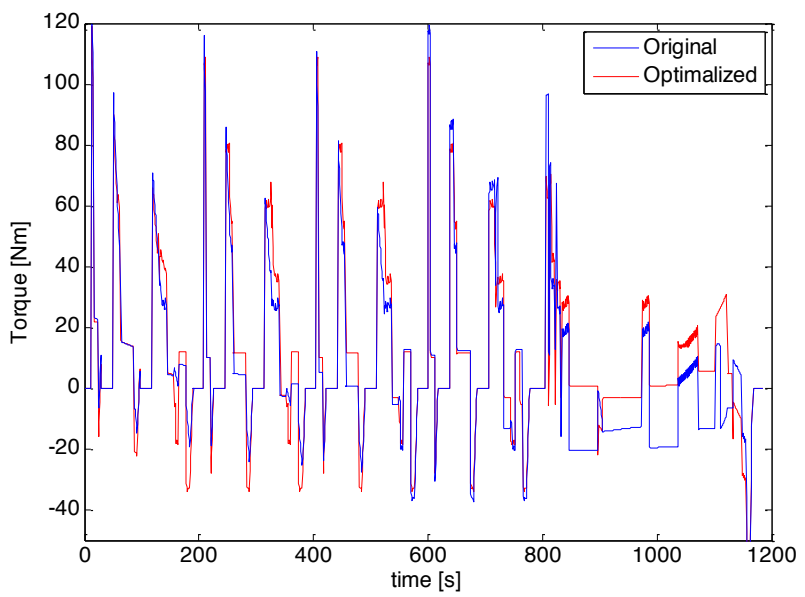

Fig. 7. Electric motor (MC) torque during NEDC

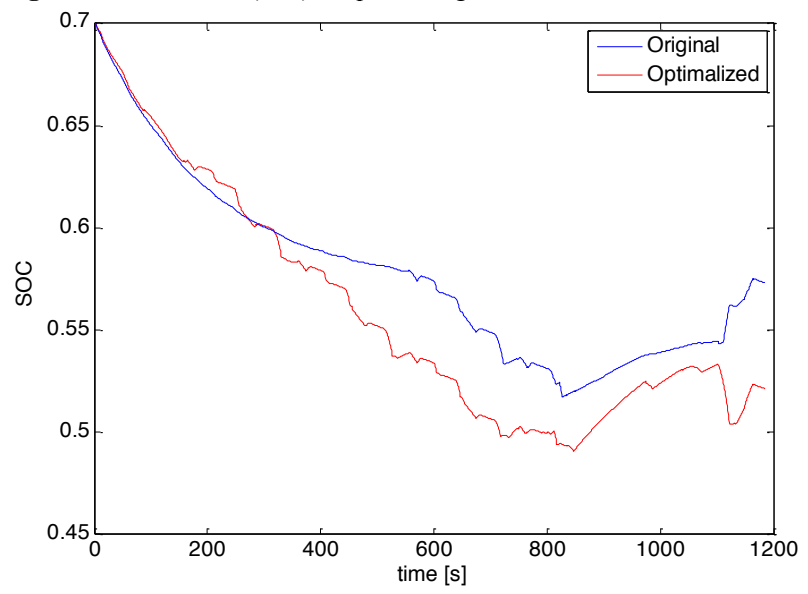

Fig. 8. State of charge of the battery during NEDC

Table 4. Comparison of original and optimized vehicle

\begin{tabular}{l|l|l}
\hline & $\begin{array}{c}\text { Original } \\
\text { Vehicle }\end{array}$ & $\begin{array}{c}\text { Optimal. } \\
\text { Vehicle }\end{array}$ \\
\hline Engine power [kW] & 43 & 17.6 \\
Motor power [kW] & 31 & 22.5 \\
Generator power [kW] & 15 & 8.1 \\
Vehicle mass $[\mathrm{kg}]$ & 1331 & 1192 \\
Fuel cons. $[1 / 100 \mathrm{~km}]$ & 5.02 & 3.35
\end{tabular}

Fuel eq. cons. $[1 / 100 \mathrm{~km}]$

Total cons. $[1 / 100 \mathrm{~km}]$

Delta SOC

Accel. 0-50 kmh [s]

Accel. 50-100 kmh [s]

Grade. at $50 \mathrm{kmh}[\%]$

$\mathrm{HC}[\mathrm{g} / \mathrm{km}]$

$\mathrm{CO}[\mathrm{g} / \mathrm{km}]$

$\mathrm{NOx}[\mathrm{g} / \mathrm{km}]$

Max. speed [kmh]

Time in $0.4 \mathrm{~km} \mathrm{[s]}$

Max. accel. $\left[\mathrm{m} / \mathrm{s}^{-2}\right]$

\section{Conclusion}

Significant fuel economy improvement during NEDC was achieved with the proposed algorithm. Optimized vehicle fuel consumption was about $30 \%$ lower at the expense of vehicle driving dynamic. It means, that optimized vehicle would be more economical, but not so agile and driver friendly as the original non-optimized one. It is caused by its operation near its maximum power during NEDC and NEDC itself is not very dynamic driving cycle.

On the other hand, optimized Prius is still able to accomplish NEDC with some reserve of power. Better dynamic parameters can be achieved by different driving cycle evaluation, but objective of this paper was to scale vehicle drivetrain components to achieve best fuel economy during NEDC.

NEDC is used to evaluate vehicle fuel consumption of cars selling in Europe. It should reflect the customers driving routine. In that case and based on this simulation, it is obvious, that drivetrains of the cars on the market todays are oversized at the expense of worse fuel economy and overall running costs.

\section{Acknowledgement}

This work was supported by the Scientific Grant Agency of the Ministry of Education of the Slovak Republic and Slovak Academy of Sciences (VEGA), under the project code $1 / 0464 / 15$. This paper was developed within the Project "Centrum excelentnosti integrovaného výskumu a využitia progresívnych materiálov a technológií v oblasti automobilovej elektroniky", ITMS 26220120055. Project is co-financed from EU funds.

This is an Open Access article distributed under the terms of the Creative Commons Attribution Licence

\section{References}

1. A. M. Lewis, J. C. Kelly and G. A. Keoleian, "Evaluating the life cycle greenhouse gas emissions from a lightweight plug-in hybrid electric vehicle in a regional context," 2012 IEEE International Symposium on Sustainable Systems and Technology, Boston, pp. 1-6, (2012) doi: 10.1109/ISSST.2012.6403806

2. L. Cheah, J. Heywood, "Meeting U.S. passenger vehicle fuel economy standards in 2016 and beyond", Energy Policy, vol. 39, no. 1, pp. 454-466, (2011) http://dx.doi.org/10.1016/j.enpol.2010.10.027

3. K. B. Wipke, M. R. Cuddy, S.D. Burch, "ADVISOR 2.1: A UserFriendly Advanced Powertrain Simulation Using a Combined
Backward/Forward Approach," Preprint prepared for IEEE Transactions on Vehicular Technology: Special Issues on Hybrid and Electric Vehicles, available online, December (2016), www.nrel.gov/docs/gen/fy99/26839.pdf

4. Neeraj, A. Kumar, "Efficient hierarchical hybrids parallel genetic algorithm for shortest path routing," 2014 5th International Conference - Confluence The Next Generation Information Technology Summit, Noida, pp. 257-261, (2014), doi: 10.1109/CONFLUENCE.2014.6949221

5. T. Vidal, T. G. Crainic, M. Gendreau, "A Hybrid Genetic Algorithm for Multidepot and Periodic Vehicle Routing Problems," 
Operations Research, vol. 60, pp. 611-624, (2012), doi: $10.1287 /$ opre. 1120.1048

6. A. Serdar Tasan, M. Gen, "A genetic algorithm based approach to vehicle routing problem with simultaneous pick-up and deliveries", Computers \& Industrial Engineering, vol. 62, no. 3, pp. 755$761,(2012)$,

http://dx.doi.org/10.1016/j.cie.2011.11.025.

7. A. Pourrajabian, M. Bakhtiari, R. Ebrahimi and H. Karimi, "Optimization of nose shape of Launch Vehicle using genetic algorithm and response surface methods," Recent Advances in Space Technologies, 2009. RAST '09. 4th International Conference on, Istanbul, 2009, pp. 221-225. doi: 10.1109/RAST.2009.5158201

8. J. Jiang, Z. Liu, W. Liu and W. Zhou, "Shape Optimization of the Cavitator for a Supercavitating Vehicle Based on Genetic Algorithm," 2009 International Conference on Information Engineering and Computer Science, Wuhan, pp. 1-4, (2009), doi: 10.1109/ICIECS.2009.5366738

9. P. Cubon, R. Radvan, V. Vavrus, „Optimization Source Structure of Electric Vehicle Using Calculation of Energy Consumption in Matlab GUI," Advances in Electrical and Electronic Engineering, vol. 13, no. 2, pp. 156-161, (2015), DOI: 10.15598/aeee.v13i2.1341

10. B. Huang, Z. Wang and Y. Xu, "Multi-Objective Genetic Algorithm for Hybrid Electric Vehicle Parameter Optimization," 2006 IEEE/RSJ International Conference on Intelligent Robots and Systems, Beijing, pp. $5177 \quad-\quad 5182$, (2006), doi: 10.1109/IROS.2006.281654

11. X. Liu, Y. Wu and J. Duan, "Optimal Sizing of a Series Hybrid Electric Vehicle Using a Hybrid Genetic Algorithm," 2007 IEEE International Conference on Automation and Logistics, Jinan, 2007 , pp. doi: 10.1109/ICAL.2007.4338737

12. L. c. Fang and S. y. Qin, "Concurrent Optimization for Parameters of Powertrain and Control System of Hybrid Electric Vehicle Based on Multi-Objective Genetic Algorithms," 2006 SICEICASE International Joint Conference, Busan, pp. 2424-2429, (2006), doi: 10.1109/SICE.2006.315114

13. M. Jain, C. Desai and S. S. Williamson, "Genetic algorithm based optimal powertrain component sizing and control strategy design for a fuel cell hybrid electric bus", 2009 IEEE Vehicle Power and Propulsion Conference, Dearborn, pp. 980-985, (2009), doi: 10.1109/VPPC.2009.5289740

14. J. Kubín and Ž. Ferková, „Influnce of driving style of a tram driver on the tram's energy consumption," 2015 International Conference on Electrical Drives and Power Electronics (EDPE), Tatranska Lomnica, pp. 417-421, (2015), doi: 10.1109/EDPE.2015.7325331

15. V. I. Herrera, H. Gaztañaga, A. Milo, A. Saez-de-Ibarra, I. Etxeberria-Otadui and T. Nieva, "Optimal Energy Management and Sizing of a Battery--Supercapacitor-Based Light Rail Vehicle With a Multiobjective Approach," IEEE Transactions on Industry Applications, vol. 52, no. 4, pp. 3367-3377, (2016), doi: 10.1109/TIA.2016.2555790
16. T. J. Boehme, B. Frank, M. Schori and T. Jeinsch, "Multi-objective optimal powertrain design of parallel hybrid vehicles with respect to fuel consumption and driving performance," 2014 European Control Conference (ECC), Strasbourg, pp. 1017-1023, (2014), doi: 10.1109/ECC.2014.6862240

17. C. Desai and S. S. Williamson, "Optimal design of a parallel Hybrid Electric Vehicle using multi-objective genetic algorithms," 2009 IEEE Vehicle Power and Propulsion Conference, Dearborn, pp. 871-876, (2009), doi: 10.1109/VPPC.2009.5289754

18. Jinming Liu and Huei Peng, "Control optimization for a power-split hybrid vehicle," 2006 American Control Conference, Minneapolis, (2006), doi: 10.1109/ACC.2006.1655400

19. A. Panday and H. O. Bansal, "A Review of Optimal Energy Management Strategies for Hybrid Electric Vehicle," International Journal of Vehicular Technology, vol. 2014, Article ID 160510, 19 pages, (2014), doi:10.1155/2014/160510

20. J. P. Gao, G. G. Zhu, E.G. Strangas, F.C. Sun, "Equivalent fuel consumption optimal control of a series hybrid electric vehicle," Proceedings of the Institution of Mechanical Engineers, Part D: Journal of Automobile Engineering, vol. 223, no. 8, pp. 10031018, (2009), doi: 10.1243/09544070JAUTO1074

21. S. Yandong, "Hybrid Genetic Algorithm Optimization of Vehicle Major Reducer," 2009 Second International Conference on Intelligent Computation Technology and Automation, Changsha, pp. 339-341, (2009), doi: 10.1109/ICICTA.2009.89

22. V. H. Wilson, Udayakumar, "Optimization of diesel engine parameters using Taguchi method and design of evolution," Journal of the Brazilian Society of Mechanical Sciences and Engineering, vol. 34, no. 4, pp. 423-428, (2012), DOI: 10.1590/S167858782012000400001

23. J. Vittek, P. Butko, M. Pospíšil and B. Ftorek, "Two approaches comparison to energy optimal position control with constant and linear torques," 2015 Intl Aegean Conference on Electrical Machines \& Power Electronics (ACEMP), 2015 Intl Conference on Optimization of Electrical \& Electronic Equipment (OPTIM) \& 2015 Intl Symposium on Advanced Electromechanical Motion Systems (ELECTROMOTION), Side, pp. 699-704, (2015), doi: 10.1109/OPTIM.2015.7427040

24. M. Birame, S. A. Bessedik, L. Mokrani, M. F. Benkhoris, "Optimal Gain of PI Speed Controller in Reluctance Synchronous Motor Using Particle Swarm Optimization", Acta Electrotechnica et Informatica, vol. 16, no. 2, pp. 42-46, (2016), DOI:10.15546/aeei2016-0014

25. S. Vaez-Zadeh, A.R. Ghasemi, "Design optimization of permanent magnet synchronous motors for high torque capability and low magnet volume", Electric Power Systems Research, vol. 74, no. 2, pp. 307 - 313, (2005), DOI: 10.1016/j.epsr.2004.11.008

26. M. Çunkaş, R. Akkaya, ,Design optimization of induction motor by genetic algorithm and comparison with existing motor," Mathematical and Computational Applications, vol. 11 no. 3, pp. 193203, (2006), doi:10.3390/mca11020193 